\title{
The contralateral reduction of intraocular pressure by timolol
}

\author{
Cynthia N Dunham, Richard F Spaide, Gerald Dunham
}

\begin{abstract}
Administration of timolol to one eye is associated with a decrease in intraocular pressure in both eyes. To further investigate this effect the contralateral decrease in intraocular pressure was measured in a three arm crossover study using a $0.1 \mathrm{mg}$ dose of timolol given topically to an eye, a $0.1 \mathrm{mg}$ dose of timolol given lingually, and a placebo given topically. Two hours after topical timolol administration the mean intraocular pressure reduction in the fellow eye was $3.1 \mathrm{~mm} \mathrm{Hg}$ compared with baseline ( $p=0.0007)$. Two hours after lingual timolol administration the mean intraocular pressure reduction was $3.9 \mathrm{~mm} \mathrm{Hg}$ compared with baseline $(p=0.0004)$. Two hours after topical administration of placebo the mean intraocular pressure reduction in the fellow eye was only $0.33 \mathrm{~mm} \mathbf{~ H g}$ $(p=0.6)$. These findings suggest the contralateral reduction in intraocular pressure from timolol is caused by systemic absorption. The significant intraocular pressure reduction obtained from lingual timolol raises the possibility that this route of drug administration may be useful in selected patients who cannot use eye drops.
\end{abstract}

(Brf Ophthalmol 1994; 78: 38-40)

Instillation of topical timolol in one eye is associated with a decrease in the intraocular pressure in the contralateral eye that is generally about one half of the intraocular pressure decrease of the treated eye. ${ }^{1-4}$ This contralateral effect has been noted with a single topical dose of timolol and the magnitude of pressure reduction seems remarkable in light of the relatively small dose of topical timolol given. Various causes have been suggested for the contralateral decrease and include systemic absorption of timolol, central nervous system mediation of intraocular pressure, and eye rubbing by the subjects. ${ }^{13}$ We sought to further investigate the contralateral pressure reduction effect of timolol by comparing the pressure reduction in the contralateral eye with the pressure reduction caused by lingual administration of timolol.

York

C N Dunham

R F Spaide

G Dunham

Department of

Ophthalmology, St

Vincent's Hospital and

Medical Center of New

York

R F Spaide

Correspondence to:

Richard F Spaide, MD, Suite

506 O’Toole Building, St

Vincent's Hospital and

Medical Center of New York, 36 Seventh Ave, New York, NY 10011, USA.

Accepted for publication

17 August 1993 mined immediately before administration of the timolol. Using a micropipette, a $20 \mu \mathrm{l}$ drop of timolol maleate $0.5 \%$ solution (Timoptic, Merck Sharp \& Dohme Ltd) was instilled into the
Sixteen healthy volunteers, aged 26 to 52 years, gave informed consent for participation in the asthma, heart disease, adverse reactions to $\beta$ blockers, diabetes mellitus, pregnancy, or ocular blockers, diabetes mellitus, pregnancy, or ocular conjunctival cul de sac of the test eye. Choice of the right or left eye was done in a random fashion. Both eyes were kept open with the head reclined and then gently closed for 1 minute without blotting or rubbing. Applanation tonometry was performed in both eyes at 5 minutes, 1 hour, and 2 hours after instillation of the drug. Blood pressure and pulse measurements were repeated at 2 hours.

After a 1 week washout period the same group of 16 volunteers was given an oral dose of $20 \mu \mathrm{l}$ of timolol maleate $0.5 \%$ solution. This dose was simply placed on the subject's tongue. Pulse and blood pressure were taken immediately before administration of the timolol. Applanation pressures were obtained at 5 minutes, 1 hour, and 2 hours after instillation of the drug. Pulse and blood pressure determinations were repeated at 2 hours.

A control group was given a topical ocular dose of $20 \mu \mathrm{l}$ of saline. Pulse, blood pressure, and intraocular pressure was measured as before. The control group was composed of 12 of the original 16 volunteers; the four others could not participate because of scheduling difficulties.

The data were analysed with descriptive statistics. Groups of data were compared using the Wilcoxon signed rank test and the MannWhitney test, non-parametric analogues of the paired and unpaired $t$ tests respectively. ${ }^{5}$ A p value of $<0.05$ was considered statistically significant.

\section{Results}

In the topically treated phase of the study the mean initial intraocular pressures in the treated $(12.91 \mathrm{~mm} \mathrm{Hg})$ and untreated eyes $(12.69 \mathrm{~mm}$ $\mathrm{Hg})$ were not significantly different $(\mathrm{p}=0.58)$. The mean drop in intraocular pressure in the treated eyes was $3.3 \mathrm{~mm} \mathrm{Hg}$ at 1 hour $(\mathrm{p}=$ 0.0004 , compared with mean initial pressure) and $4.4 \mathrm{~mm} \mathrm{Hg}$ at 2 hours $(p=0.0004)$. The eyes was $2.1 \mathrm{~mm} \mathrm{Hg}$ at 1 hour $(\mathrm{p}=0.0049$, compared with mean initial pressure) and $3 \cdot 1$ $\mathrm{mm} \mathrm{Hg}(\mathrm{p}=0.0007)$ at 2 hours (Fig 1). There was no difference between the pretreatment and post-treatment systolic or diastolic blood pressure. There was a significant reduction in pulse, from a mean pretreatment pulse of 74.9 to a mean post-treatment pulse of $67 \cdot 3(p=0 \cdot 0045)$.

In the lingual application phase of the study the mean initial intraocular pressures in the two eyes were 13.16 and $13.3 \mathrm{~mm} \mathrm{Hg}$. These pressures were not significantly different from each other or from the mean initial pressures of the topical phase of the study. During the lingual phase of the study the mean drop in intraocular pressure in the eye that was the treated eye in the mean drop in intraocular pressure of the fellow 
Figure 1. Intraocular pressure in the treated eye after a uniocular dose of saline (O), $0.1 \mathrm{mg}$ timolol (O), and the intraocular pressure of the same eye after a $0.1 \mathrm{mg}$ timolol dose to the tongue $(\diamond)$.

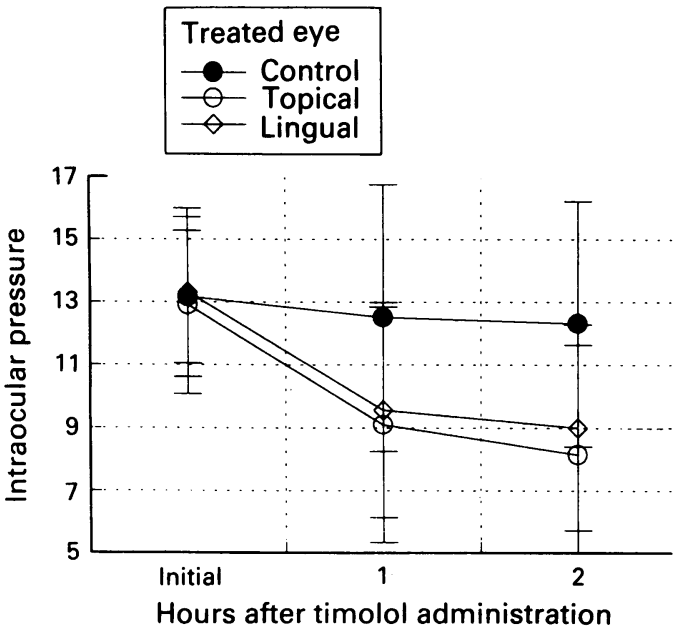

topical study was $3 \cdot 1 \mathrm{~mm} \mathrm{Hg}(\mathrm{p}=0 \cdot 0007$, compared with mean initial pressure) at 1 hour and $3.6 \mathrm{~mm} \mathrm{Hg}$ at 2 hours $(p=0.0007)$. Likewise, the mean drop in intraocular pressure in the eye that was the fellow eye of the topical phase of the study was $3.2 \mathrm{~mm} \mathrm{Hg}$ ( $p=0.0007$, compared with mean initial pressure) at 1 hour and $3.9 \mathrm{~mm}$ $\mathrm{Hg}(\mathrm{p}=0.0004)$ at 2 hours (Fig 2). There was no difference between the pretreatment and posttreatment systolic or diastolic blood pressure in the lingual application phase of the study. There was a significant decrease in pulse in the lingual application phase from a mean pretreatment pulse of 70.9 to a mean post-treatment pulse of $66.6(p=0.0086)$

In the placebo phase of the study there was no change from baseline in the mean intraocular pressure of the treated eye. The mean intraocular pressure in the fellow eye in the placebo arm of the study decreased $0.33 \mathrm{~mm} \mathrm{Hg}$ over 2 hours, an amount that did not reach statistical significance $(p=0.6)$. The changes in systolic blood pressure, diastolic blood pressure, and pulse were not statistically significant.

The mean intraocular pressure drop of the treated eye in the topical application phase of the study was greater than the drop in intraocular pressure of the same eye in the lingual phase at 1 and 2 hours, but the difference did not reach statistical significance $(p=0.8$ and $p=0.27$ respectively). On the other hand, the mean

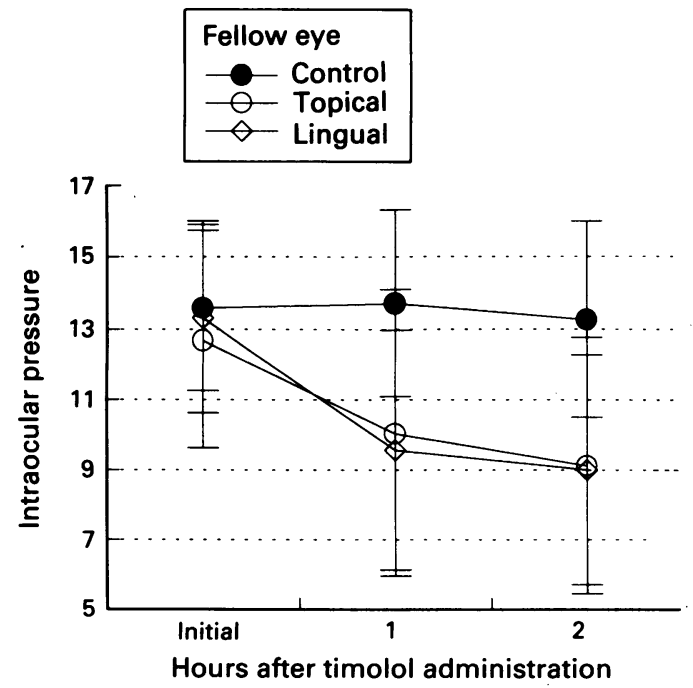

intraocular pressure drop of the fellow eye in the topical application phase was less than the drop in intraocular pressure of the same eye in the lingual application phase of the study at 1 and 2 hours, but the difference did not reach statistical significance $(p=0.069$ and $p=0.23$ respectively). The change in pulse rate in the topical group compared with the lingual group was not significantly different, but there was a significant difference in the change in pulse rate between the control and the topical and lingual groups (Fig 3).

\section{Discussion}

As expected, topical application of timolol caused a reduction in intraocular pressure in the treated eye as well as the untreated fellow eye. At 2 hours the contralateral eye experienced a drop in intraocular pressure that was $70.4 \%$ of the drop in the treated eye, which was somewhat greater than the contralateral effect seen in past studies. ${ }^{1-4}$ The reason for the greater contralateral effect is a matter of speculation, but all studies had both small sample sizes and probable differences in subject selection that might have preferentially biased the results obtained.

Lingual application of timolol also caused an intraocular pressure reduction. This reduction was less than that obtained from direct topical treatment, but was somewhat greater than the contralateral effect seen in the topical application phase of the study. The similar reduction in pulse noted by both routes of administration suggests that timolol may be systemically absorbed to the same degree by both routes. Past studies have demonstrated an intraocular pressure reduction from oral ingestion of $\beta$ adrenergic blocking agents given in pill form. ${ }^{67}$ These studies differ from the present study in several ways. The doses administered in the past studies were orders of magnitude greater than the $0.1 \mathrm{mg}$ dose given in this study.${ }^{67}$ Past studies used pills which were swallowed. It has been shown that when $\beta$ adrenergic blocking agents are swallowed they undergo a first pass effect in the liver and this reduces the amount of drug reaching end organs. ${ }^{8}$ The small volume given to the subjects in the present study was difficult to swallow, and may have resulted in direct absorption through the oral mucosa, thus bypassing the first pass effect in the liver. ${ }^{9}$

Topical application of timolol to the eye

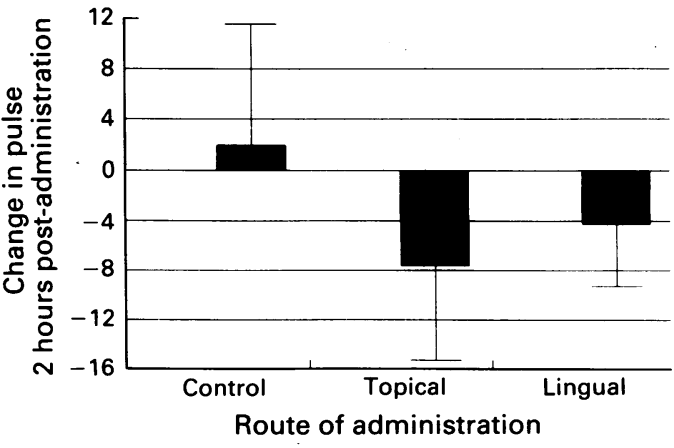

Figure 3 Change in pulse rate compared with baseline after a uniocular dose of saline, $0.1 \mathrm{mg}$ timolol, and $0.1 \mathrm{mg}$ timolol dose to the tongue. 
results in systemic absorption, mainly through the conjunctiva and mucosa of the nasopharynx. In an animal model, application of timolol in one eye produced measurable levels of drug in the contralateral eye. ${ }^{10}$ The ocular hypotensive effect of timolol is much less in animal than humans and was not measured in that study. ${ }^{10}$ The results of the present study suggest that the contralateral reduction of intraocular pressure from timolol is due to systemic absorption. The magnitude of the contralateral intraocular pressure reduction in this and previous studies raises questions about the penetration and pharmacodynamics of timolol in the treated eye.

Although topical application of timolol readily elevates the aqueous humour concentration of the drug, experiments in animal models show that timolol readily binds to melanin pigment of the iris ${ }^{11}$ and is also eliminated from the iris by the blood circulation. The net fluid flow is from the ciliary body to the anterior chamber, resulting in aqueous flow dynamics that reduces access of timolol to the ciliary processes. ${ }^{12}$ The combination of these factors leads to decreased penetration of timolol into the posterior chamber, ${ }^{10}$ thus reducing passage of the drug directly to the ciliary body. It is possible that the intraocular pressure reduction seen in the treated eye is the result of the combined effects of the direct penetration into the eye as well as systemic absorption of the drug.

The main reason $\beta$ blockers are given topically is to avoid systemic side effects. These side effects may limit the use of $\beta$ blockers among some glaucoma patients. Punctal occlusion appears to reduce systemic absorption. ${ }^{13}$ For most patients, however, the systemic side effects of low dose $\beta$ blockers appear to be well tolerated. The significant intraocular pressure reduction from a single lingual dose of $0.1 \mathrm{mg}$ of timolol observed in this study suggests that this avenue of drug administration may be useful for selected patients who do not have sufficient manual dexterity to apply eye drops in the conventional manner. Additional study of this avenue is necessary, particularly to evaluate the short term escape and long term drift seen in topically applied timolol, ${ }^{14}$ as well as possible systemic side effects.

1 Zimmerman TJ, Kaufman HE. Timolol. A $\beta$-adrenergic blocking agent for the treatment of glaucoma. Arch Ophthalmol 1977; 95: 601-4

2 Zimmerman TJ, Kaufman HE. Timolol. Dose response and duration of action. Arch Ophthalmol 1977; 95: 605-7.

3 Radius RL, Diamond GR, Pollack IR, Langham ME. Timolol. A new drug for management of chronic simple glaucoma. Arch Ophthalmol 1978; 96: 1003-8

4 Zimmerman TJ, Kass MA, Yablonski ME, Becker B. Timolol maleate. Efficiency and safety. Arch Ophthalmol 1979; 97: 656-8.

5 Hintze JL. Solo statistical system. Los Angeles: BMDP Statistical Software, 1991: 280

6 Alm A, Wickstrom P, Ekstrom C, Ohrman L. The effect of metaprolol on intraocular pressure in glaucoma. Acta Ophthalmol 1979; 57: 236-42.

7 Batchelor ED, O'Day DM, Shand DG, Wood AL. Interaction of topical and oral timolol in glaucoma. Ophthalmology 1979; 86: $60-5$

8 Shell JW. Ophthalmic drug delivery systems. Surv Ophthalmol 1984; 29: 117-28.

9 Hoskins HD Jr, Kass M. Becker-Schaffer's diagnosis and therapy of the glaucomas. 6th ed. St Louis: Mosby, 1989: 460 .

10 Urtti A, Salminen L. A comparison between iris-ciliary body concentration and receptor affinity of timolol. Acta Ophthalmol 1985; 63: 16-8

11 Araie M, Takase M, Sakai Y, Ishii Y, Yokoyama Y, Kitagawa Y. Beta-adrenergic blockers: ocular penetration and binding to uveal pigment. Fpn F Ophthalmol 1982; 26: 248-63.

12 Raviola $G$. The structural basis of the blood ocular barriers. Exp Eye Res 1977; 25: 27-63.

13 Zimmerman TJ, Kooner KS, Kandarakis AS, Ziegler LP. Improving the therapeutic index of topically applied ocular drugs. Arch Ophthalmol 1984; 102: 551-3.

14 Steinert RF, Thomas JV, Boger WP. Long-term drift and continued efficacy after multiyear timolol therapy. Arch Ophthalmol 1981;99: 100-3. 